CUBO A Mathematical Journal Vol.15, № 02, (105-110). June 2013

\title{
An iterative method for finite family of hemi contractions in Hilbert space
}

Balwant Singh ThakuR

School of Studies in Mathematics,

Pt.Ravishankar Shukla University, Raipur,492010, India.

balwantst@gmail.com

\begin{abstract}
We consider the problem of finding a common fixed point of $\mathrm{N}$ hemicontractions defined on a compact convex subset of a Hilbert space, an algorithm for solving this problem will be studied. We will prove strong convergence theorem for this algorithm.
\end{abstract}

\section{RESUMEN}

Consideramos el problema de búsqueda de un punto fijo común de $\mathrm{N}$ hemicontracciones definida sobre un subconjunto convexo compacto de un espacio de Hilbert. Se estudiará un algoritmo para resolver este problema. Probaremos el teorema de convergencia fuerte para este algoritmo.

Keywords and Phrases: Hemicontraction, Mann iteration, implicit iteration, common fixed point.

2010 AMS Mathematics Subject Classification: 47H09,47H10. 


\section{Introduction}

Let $\mathrm{H}$ be a Hilbert space and let $\mathrm{K}$ be a nonempty subset of $\mathrm{H}$. A map $\mathrm{T}: \mathrm{K} \rightarrow \mathrm{K}$ is called nonexpansive if

$$
\|\mathrm{T} x-\mathrm{T} y\| \leq\|x-y\|, \quad \forall x, y \in K .
$$

An important generalization of nonexpansive mapping is pseudocontractive mapping. A mapping $\mathrm{T}: \mathrm{K} \rightarrow \mathrm{K}$ is said to be pseudocontractive if, $\forall x, y \in \mathrm{K}$,

$$
\|\mathrm{T} x-\mathrm{T} y\|^{2} \leq\|x-y\|^{2}+\|(I-T) x-(I-T) y\|^{2}
$$

holds. $T$ is said to be strongly pseudocontractive if, there exists $k \in(0,1)$ such that,

$$
\|\mathrm{Tx}-\mathrm{Ty}\|^{2} \leq\|x-y\|^{2}+k\|(I-T) x-(I-T) y\|^{2}, \quad \forall x, y \in K .
$$

For importance of fixed points of pseudocontractive mappings one may refer [1].

Iterative methods for approximating fixed points of nonexpansive mappings have been extensively studied (see e.g. 2, 3, 4, 7), but, iterative methods for approximating pseudocontractive mappings are far less developed than those of nonexpansive mappings. However, on the otherhand pseudocontractions have more powerful applications than nonexpansive mappings in solving nonlinear inverse problems. In recent years many authors have studied iterative approximation of fixed point of strongly pseudocontractive mappings. Most of them used Mann's iteration process 6]. But in the case of pseudocontractive mapping, it is well known that Mann's iteration fails to converge to fixed point of Lipschitz pseudocontractive mappings in a compact convex subset of a Hilbert space. In 1974, Ishikawa [5] introduced an iteration process which converges to a fixed point of Lipschitz pseudocontractive mapping in a compact convex subset of a Hilbert space. Qihou [8], extended result of Ishikawa to slightly more general class of Lipschitz hemicontractive mappings. A mapping $\mathrm{T}: \mathrm{K} \rightarrow \mathrm{K}$ is said to be hemicontractive if $\mathrm{F}(\mathrm{T}) \neq \emptyset$ and

$$
\|T x-p\|^{2} \leq\|x-p\|^{2}+\|x-T x\|^{2}, \quad \forall x \in K, \quad p \in F(T)
$$

where $F(T):=\{x \in K: T x=x\}$ is the fixed point set of $T$.

It is easy to see that the class of pseudocontractive mappings with fixed points is a subclass of the class of hemicontractive mappings.

More recently, Rafiq [9], proposed Mann type implicit iteration process to approximate fixed points of hemicontractive mapping defined in a compact convex subset of a Hilbert space.

For arbitrary chosen $x_{0} \in \mathrm{K}$ the iteration process is given by

$$
x_{n}=\alpha_{n} x_{n-1}+\left(1-\alpha_{n}\right) T x_{n}
$$


where $\left\{\alpha_{n}\right\}$ is a real sequence in $[0,1]$ satisfying some appropriate conditions.

The purpose of this paper to study the problem of finding a point $x$ such that

$$
x \in \bigcap_{i=1}^{N} \operatorname{Fix}\left(T_{i}\right)
$$

where $N \geq 1$ is a positive integer and $\left\{T_{i}\right\}_{i=1}^{N}$ are $N$ hemicontractive mappings defined on a compact convex subset $\mathrm{K}$ of a Hilbert space $\mathrm{H}$. We study the strong convergence of the algorithm which generates a sequence $\left\{x_{n}\right\}$ in the following way:

$$
x_{n}=\alpha_{n} x_{n-1}+\left(1-\alpha_{n}\right) \sum_{i=1}^{N} \lambda_{i}^{(n)} T_{i} x_{n}
$$

where the sequence of weights $\left\{\lambda_{i}^{(n)}\right\}_{i=1}^{N}$ satisfies appropriate assumptions.

\section{Preliminaries}

Following well known identity holds in a Hilbert space $\mathrm{H}$ :

$$
\|(1-\lambda) x+\lambda y\|^{2}=(1-\lambda)\|x\|^{2}+\lambda\|y\|^{2}-\lambda(1-\lambda)\|x-y\|^{2}
$$

for all $x, y \in H$ and $\lambda \in[0,1]$.

We shall use the following lemma to prove our main result:

Lemma 2.1. [10] Suppose $\left\{\rho_{n}\right\}$ and $\left\{\sigma_{n}\right\}$ are two sequences of nonnegative numbers such that for some real number $\mathrm{N}_{0} \geq 1$,

$$
\rho_{\mathrm{n}+1} \leq \rho_{\mathrm{n}}+\sigma_{\mathrm{n}} \quad \forall \mathrm{n} \geq \mathrm{N}_{\mathrm{o}}
$$

(a) If $\sum \sigma_{\mathrm{n}}<\infty$ then, $\lim \rho_{\mathrm{n}}$ exists.

(b) If $\sum \rho_{n}<\infty$ and $\left\{\rho_{n}\right\}$ has a subsequence converging to zero, then $\lim \rho_{n}=0$.

Given an integer $N \geq 1$, for each $1 \leq i \leq N$, assume that $T_{i}: K \rightarrow K$ is a hemicontractive mapping. Then the family $\left\{T_{i}\right\}_{i=1}^{N}$ is said to satisfy condition $\mathbf{B}$ if

$$
\bigcap_{i=1}^{N} \operatorname{Fix}\left(T_{i}\right) \neq \emptyset, \quad \text { and } \operatorname{Fix}\left(\sum_{i=1}^{N} \lambda_{i} T_{i}\right)=\bigcap_{i=1}^{N} \operatorname{Fix}\left(T_{i}\right)
$$

where $\left\{\lambda_{i}\right\}$ is a positive sequence such that $\sum_{i=1}^{N} \lambda_{i}=1$. 
Proposition 2.2. Let $\mathrm{N} \geq 1$ be a given integer. For each $1 \leq \mathrm{i} \leq \mathrm{N}$, assume that $\mathrm{T}_{\mathrm{i}}: \mathrm{K} \rightarrow \mathrm{K}$ is a hemicontractive mapping and the family $\left\{\mathrm{T}_{i}\right\}_{i=1}^{\mathrm{N}}$ satisfies the condition B. Then $\sum_{i=1}^{\mathrm{N}} \lambda_{i} \mathrm{~T}_{i}$ is a hemicontractive mapping.

Proof. Let us consider the case of $\mathrm{N}=2$. Set $\mathrm{V}=(1-\lambda) \mathrm{T}_{1}+\lambda \mathrm{T}_{2}$, where $\lambda \in(0,1)$, where $\mathrm{T}_{1}, \mathrm{~T}_{2}$ are hemicontractions. We have to prove that

$$
\|\mathrm{V} x-\mathrm{p}\|^{2} \leq\|x-\mathrm{p}\|^{2}+\|(\mathrm{I}-\mathrm{V}) \mathrm{x}\|^{2} \quad \forall x \in \mathrm{K}, \mathrm{p} \in \mathrm{Fix}(\mathrm{V})
$$

We have

$$
\begin{aligned}
\|(\mathrm{I}-\mathrm{V}) x\|^{2} & =\left\|\left(\mathrm{I}-\left((1-\lambda) \mathrm{T}_{1}+\lambda \mathrm{T}_{2}\right)\right) x\right\|^{2} \\
& =(1-\lambda)\left\|\left(\mathrm{I}-\mathrm{T}_{1}\right) x\right\|^{2}+\lambda\left\|\left(\mathrm{I}-\mathrm{T}_{2}\right) x\right\|^{2}-\lambda(1-\lambda)\left\|\left(\mathrm{T}_{1}-\mathrm{T}_{2}\right) x\right\|^{2}
\end{aligned}
$$

so,

$$
\begin{aligned}
\|V x-p\|^{2}= & \left\|(1-\lambda)\left(T_{1} x-p\right)+\lambda\left(T_{2} x-p\right)\right\|^{2} \\
= & (1-\lambda)\left\|T_{1} x-p\right\|^{2}+\lambda\left\|T_{2} x-p\right\|^{2}-\lambda(1-\lambda)\left\|T_{1} x-T_{2} x\right\|^{2} \\
\leq & (1-\lambda)\left[\|x-p\|^{2}+\left\|\left(I-T_{1}\right) x\right\|^{2}\right]+\lambda\left[\|x-p\|^{2}+\left\|\left(I-T_{2}\right) x\right\|^{2}\right] \\
& -\lambda(1-\lambda)\left\|T_{1} x-T_{2} x\right\|^{2} \\
= & \|x-p\|^{2}+\|(I-V) x\|^{2} .
\end{aligned}
$$

Hence $\mathrm{V}$ is a hemicontraction. The general case can be proved by induction.

\section{Main result}

Theorem 3.1. Let $\mathrm{K}$ be a compact convex subset of a Hilbert space $\mathrm{H}$. Let $\mathrm{N} \geq 1$ be an integer. For each $\mathrm{n} \geq 1$, assume that $\left\{\lambda_{i}^{(\mathrm{n})}\right\}_{i=1}^{\mathrm{N}}$ is a finite sequence of positive numbers such that $\sum_{i=1}^{\mathrm{N}} \lambda_{i}^{(\mathrm{n})}=1$ and $\inf _{\mathrm{n} \geq 1} \lambda_{i}^{(\mathrm{n})}>0$ for all $1 \leq \mathrm{i} \leq \mathrm{N}$. For each $1 \leq \mathrm{i} \leq \mathrm{N}$, let $\mathrm{T}_{\mathrm{i}}: \mathrm{K} \rightarrow \mathrm{K}$ is a hemicontractive mapping and the family $\left\{\mathrm{T}_{i}\right\}_{i=1}^{\mathrm{N}}$ satisfies the condition $\mathrm{B}$. For arbitrary chosen $\mathrm{x}_{0} \in \mathrm{K}$, let $\left\{\mathrm{x}_{\mathrm{n}}\right\}$ be a sequence generated by the algorithm (1), where the sequence $\left\{\alpha_{n}\right\} \subset[\delta, 1-\delta]$ for some $\delta \in(0,1)$. Then $\left\{x_{n}\right\}$ converges strongly to a common fixed point of the family $\left\{\mathrm{T}_{i}\right\}_{i=1}^{N}$.

Proof. Write, for each $n \geq 1$,

$$
S_{n}=\sum_{i=1}^{N} \lambda_{i}^{(n)} T_{i} .
$$

By the Proposition 2.2, each $S_{n}$ is hemicontractive on $\mathrm{K}$, and the algorithm (1) can be rewritten as,

$$
x_{n}=\alpha_{n} x_{n-1}+\left(1-\alpha_{n}\right) S_{n} x_{n}
$$


For $p \in F:=\bigcap_{i=1}^{N} F i x\left(T_{i}\right)$, we have

$$
\begin{aligned}
\left\|x_{n}-p\right\|^{2}= & \left\|\alpha_{n}\left(x_{n-1}-p\right)+\left(1-\alpha_{n}\right)\left(S_{n} x_{n}-p\right)\right\|^{2} \\
= & \alpha_{n}\left\|x_{n-1}-p\right\|^{2}+\left(1-\alpha_{n}\right)\left\|S_{n} x_{n}-p\right\|^{2}-\alpha_{n}\left(1-\alpha_{n}\right)\left\|x_{n-1}-S_{n} x_{n}\right\|^{2} \\
\leq & \alpha_{n}\left\|x_{n-1}-p\right\|^{2}+\left(1-\alpha_{n}\right)\left[\left\|x_{n}-p\right\|^{2}+\left\|x_{n}-S_{n} x_{n}\right\|^{2}\right] \\
& \quad-\alpha_{n}\left(1-\alpha_{n}\right)\left\|x_{n-1}-S_{n} x_{n}\right\|^{2}
\end{aligned}
$$

Also,

$$
\begin{aligned}
\left\|x_{n}-S_{n} x_{n}\right\|^{2} & =\left\|\alpha_{n} x_{n-1}+\left(1-\alpha_{n}\right) S_{n} x_{n}-S_{n} x_{n}\right\|^{2} \\
& =\alpha_{n}^{2}\left\|x_{n-1}-S_{n} x_{n}\right\|^{2} .
\end{aligned}
$$

Using (3) and (4), we have

$$
\left\|x_{n}-p\right\|^{2} \leq\left\|x_{n-1}-p\right\|^{2}-\left(1-\alpha_{n}\right)^{2}\left\|x_{n-1}-S_{n} x_{n}\right\|^{2} .
$$

From the condition $\left\{\alpha_{n}\right\} \subset[\delta, 1-\delta]$ for some $\delta \in(0,1)$, we conclude that

$$
\left\|x_{n}-p\right\|^{2} \leq\left\|x_{n-1}-p\right\|^{2}-\delta^{2}\left\|x_{n-1}-S_{n} x_{n}\right\|^{2}
$$

holds for all $p \in F$. Now,

$$
\delta^{2}\left\|x_{n-1}-S_{n} x_{n}\right\|^{2} \leq\left\|x_{n-1}-p\right\|^{2}-\left\|x_{n}-p\right\|^{2}
$$

and hence,

$$
\begin{aligned}
\delta^{2} \sum_{j=1}^{\infty}\left\|x_{j-1}-S_{j} x_{j}\right\|^{2} & \leq \sum_{j=1}^{\infty}\left(\left\|x_{j-1}-p\right\|^{2}-\left\|x_{j}-p\right\|^{2}\right) \\
& =\left\|x_{0}-p\right\|^{2}
\end{aligned}
$$

implies,

$$
\delta^{2} \sum_{j=1}^{\infty}\left\|x_{j-1}-S_{j} x_{j}\right\|^{2}<\infty
$$

So,

$$
\lim _{n \rightarrow \infty}\left\|x_{n-1}-S_{n} x_{n}\right\|=0
$$

From (4), we have

$$
\lim _{n \rightarrow \infty}\left\|x_{n}-S_{n} x_{n}\right\|=0 .
$$

Without loss of generality, we may assume that

$$
\lambda_{i}^{\left(n_{l}\right)} \rightarrow \lambda_{i} \quad(\text { as } l \rightarrow \infty), \quad 1 \leq i \leq N .
$$

It is easily seen that each $\lambda_{i}>0$ and $\sum_{i=1}^{N} \lambda_{i}=1$. We also have

$$
S_{n_{l}} x \rightarrow S x \quad(\text { as } l \rightarrow \infty), \quad \text { for all } x \in K,
$$


where

$$
S=\sum_{i=1}^{N} \lambda_{i} T_{i}
$$

Since $K$ is compact, there is a subsequence $\left\{x_{n_{j}}\right\}$ of $\left\{x_{n}\right\}$ which converges to a fixed point of $S$, say $z$. Using (6), we have

$$
\left\|x_{n}-z\right\|^{2} \leq\left\|x_{n-1}-z\right\|^{2}-\delta^{2}\left\|x_{n-1}-S x_{n}\right\|^{2}
$$

In view of Lemma 2.1 and (7), we conclude that

$$
\left\|x_{n}-z\right\| \rightarrow 0 \text { as } n \rightarrow \infty
$$

i.e. $x_{n} \rightarrow z$ as $n \rightarrow \infty$.

This completes the proof.

\section{Acknowledgements}

The author is supported by a project (FN-41-1390/2012) of University Grants Commission of India.

Received: December 2011. Accepted: September 2012.

\section{References}

[1] Browder,F.E. Nonlinear operators and nonlinear equations of evolution in Banach spaces, Proc. Sympos. Pure Math., XVIII (2) (1976).

[2] Browder,F.E. and Petryshyn,W.V., Construction of fixed points of nonlinear mappings in Hilbert spaces, J. Math. Anal. Appl., 20 (1967), 197-228.

[3] Chidume,C.E., Li,J. and Udomene,A., Convergence of paths and approximation of fixed points of asymptotically nonexpansive mappings, Proc. Amer. Math. Soc., 133 (2) (2004), 473-480.

[4] Halpern,B., Fixed points of nonexpansive maps', Bull. Amer. Math. Soc., 73 (1967), 957-961.

[5] Ishikawa,S. Fixed point by a new iteration method, Proc. Amer. Math. Soc., 4 (1974), 147-150.

[6] Mann,W.R. Mean value methods in iteration, Proc. Amer. math. Soc., 4 (1953), 506-510.

[7] Opial,Z., Weak convergence of the sequence of successive approximation for nonexpansive mappings, Bull. Amer. Math. Soc., 76 (1967), 591-597.

[8] Qihou,L. The convergence theorems of the sequences of Ishikawa iterates for hemicontractive mappings, J. Math. Anal. Appl., 148 (1990), 55-62.

[9] Rafiq,A. On Mann iteration in Hilbert spaces, Nonlinear Analysis, 66 (2007), 2230-2236.

[10] Tan,K.K. and Xu,H.K., Approximating fixed points of nonexpansive mappings by the Ishikawa iteration process, J. Math. Anal. Appl., 178 (1993), 301-308. 